\title{
Perfil industrial de Minas Gerais e a hipótese de desindustrialização estadual*
}

\author{
Michele Polline Veríssimo* \\ Sávio de Carvalho Araújo
}

Recebido: 23/04/2015 Versão Revisada (entregue): 01/10/2015 Aprovado: 16/10/2015

\section{RESUMO}

Este artigo analisa o perfil industrial de Minas Gerais nos anos 2000, com o objetivo de avaliar o desempenho da indústria de transformação no estado conforme a hipótese de desindustrialização. Verifica-se que a indústria de transformação perdeu peso relativo no produto estadual e apresentou deterioração em seu conteúdo tecnológico, ao passo que houve avanço da participação da indústria extrativa, na qual o estado possui vantagens comparativas. A análise de cointegração e a estimação de Modelos de Vetores de Correção de Erros sugerem algum indício de desindustrialização em Minas Gerais, manifesto na importância de uma taxa de câmbio real depreciada para estimular a produção industrial de transformação do estado no longo prazo.

PalaVras-CHAVE | Perfil Industrial; Desindustrialização; Minas Gerais

Códigos-JEL | L16; L60; O14

\footnotetext{
* Agradecemos à Fundação de Amparo à Pesquisa do Estado de Minas Gerais (Fapemig) e ao Conselho Nacional de Desenvolvimento Científico e Tecnológico (CNPq) pelo apoio financeiro à pesquisa e aos pareceristas da RBI pelas sugestōes e comentários ao trabalho.

** Universidade Federal de Uberlândia (UFU), Uberlândia (MG), Brasil. E-mail: michele@ie.ufu.br

*** Universidade Federal de Uberlândia (UFU), Uberlândia (MG), Brasil. E-mail: sca_carvalhoaraujo@hotmail.com
} 


\title{
Minas Gerais industrial profile and the state deindustrialization hypothesis
}

\begin{abstract}
This paper analyzes the Minas Gerais industrial profile over the 2000s in order to check the manufacturing sector performance in the state, according to the deindustrialization hypothesis. The evidences indicate that the manufacturing sector lost share on state product and showed some deterioration in its technological content. On the other hand, the mining sector, where the state has comparative advantages, increased its participation. The cointegration analysis and Error Correction Vector Models estimation suggest some evidence of deindustrialization in Minas Gerais, manifest by the importance of a depreciated real exchange rate to stimulate the state manufacturing production in the long run.
\end{abstract}

KeYwORDS | Industry Profile; Deindustrialization; Minas Gerais

JEL CODES | L16; L60; O14 


\section{Introdução}

A indústria é tratada por alguns autores na literatura econômica como componente fundamental para o crescimento econômico, pois tal setor seria dotado de economias de escala e efeitos de transbordamento para o restante da economia, estimulando cadeias produtivas industriais e não industriais. Kaldor (1966), por exemplo, sintetiza a importância do setor industrial, postulando sobre a existência de uma correlação entre o crescimento do produto e o aumento da produção na indústria, a qual passa pela ampliação da produtividade industrial que se espalha para os demais setores da economia.

A conjuntura que marcou o processo de estabilização da economia brasileira a partir de meados da década de 1990 (Plano Real), com a política de âncora cambial, abertura comercial, altas taxas de juros, entre outras, afetou a matriz industrial brasileira, suscitando um importante debate acerca de um possível processo de desindustrialização no país e suas consequências para o crescimento econômico no longo prazo. A relação entre a aparente tendência desindustrializante da economia brasileira, com vistas a um movimento de especialização da pauta produtiva e exportadora em produtos básicos e semielaborados, e a obtenção de menores taxas de crescimento do PIB (Produto Interno Bruto) ganhou ainda mais importância, uma vez que eventos verificados em boa parte da década de 2000 (apreciação cambial e elevados preços internacionais das commodities) reforçam o argumento de que tais produtos possuem menores efeitos indutores sobre o crescimento econômico.

Cabe ressaltar que as possíveis alterações do padrão industrial da economia brasileira envolvem disparidades sobre as diferentes regiōes/estados do país. Assim, é sabido que o estado de Minas Gerais possui, historicamente, uma forte relação com a indústria e a agropecuária, destacando-se pela inserção em mercados de minerais ferrosos, ouro, siderúrgico, café e automotivo. Todavia, na última década, alteraçôes na composição da atividade industrial do estado sinalizam para uma expansão da indústria extrativa (ligada à exploração de recursos naturais) em detrimento das atividades de transformação (dotadas de maior conteúdo tecnológico).

Assim, este artigo tem o objetivo de discutir o perfil industrial do estado de Minas Gerais nos anos 2000. O trabalho parte da seguinte pergunta: é possível verificar sinais de desindustrialização no estado, em termos de uma perda de desempenho relativo da sua indústria de transformação? Toma-se como hipótese que o contexto de apreciação cambial, elevados preços internacionais das commodities, altas taxas de juros, abertura comercial e demanda externa crescente por produtos primários, 
o qual favorece e reforça a especialização da estrutura produtiva e exportadora local em produtos intensivos em recursos naturais, pode acarretar um desempenho menos favorável da indústria de transformação com conteúdo tecnológico mais elaborado diante dos demais setores da economia, sinalizando alguma evidência de desindustrialização relativa no estado.

Para investigar a questão, o artigo analisa dados relativos à estrutura industrial de Minas Gerais e estima um modelo econométrico que busca avaliar os efeitos da conjuntura econômica sobre a produção da indústria extrativa e de transformação do estado nos anos 2000.

$\mathrm{O}$ artigo está estruturado em cinco seções, incluindo esta introdução. A seguir são sistematizados os principais conceitos de desindustrialização e retratada a literatura sobre este evento em contextos regionais. Posteriormente, é ilustrado o perfil industrial de Minas Gerais no período 2000-2012. Expõe-se a metodologia utilizada para investigar os efeitos da taxa de câmbio real, preços de commodities, abertura comercial e taxa de juros sobre a produção industrial do estado e discutem-se os resultados obtidos. Por fim, são apresentadas as considerações finais.

\section{Revisão da literatura}

O problema da desindustrialização engloba diversos conceitos. Para Rowthorn e Ramaswamy (1999), este processo corresponde à diminuição persistente do emprego industrial no emprego total de uma economia. Essa definição foi ampliada por Tregenna (2009) para também agregar a redução da participação da indústria no valor adicionado total. Clark (1957) aponta que este processo pode ser tomado como natural, pois, à medida que a renda aumenta, cresce a demanda por produtos industriais, estimulando o investimento na indústria até um ponto de inversão, em que a participação da indústria se estabiliza e posteriormente cai, com os serviços passando a absorver o incremento de demanda outrora destinada aos produtos industriais.

Outros autores destacam a influência das políticas econômicas como indutoras dos processos de desindustrialização. Nesse sentido, Palma (2005) defende que a mudança do regime de substituição de importações por políticas liberalizantes (abertura comercial e financeira) na década de 1990 teria provocado um retrocesso da estrutura produtiva em direção a uma especialização em produtos primários nos quais os países teriam vantagens comparativas ricardianas. Cano (2012) sublinha que, no caso brasileiro, o processo de "desindustrialização precoce e nociva" teria 
como causas a política de câmbio valorizado, a abertura desregrada, a elevada taxa de juros no país, a redução do investimento estrangeiro direto e a desaceleração da economia mundial. Nesse contexto, observa-se forte tendência de reprimarização da pauta exportadora, na qual a participação dos produtos manufaturados no volume total foi reduzida, enquanto as importaçôes de bens de consumo duráveis aumentaram, deslocando a demanda por manufaturas para o exterior.

A desindustrialização também é vista como consequência do problema da doença holandesa. Nesses termos, Bresser-Pereira e Marconi (2008) afirmam que a escalada de preço das commodities, a partir de 2003, motivada pelo crescimento da demanda global, principalmente chinesa, permitiu que os exportadores brasileiros desses produtos se posicionassem no comércio mundial mesmo diante de uma taxa de câmbio real apreciada, ou, no mínimo, acima da "taxa de câmbio de equilíbrio industrial", que seria aquela necessária para garantir rentabilidade ao setor de comercializáveis que utilizam tecnologia sofisticada. Em linha, Marconi e Rocha (2012) corroboram a importância do câmbio como alavanca da dinâmica industrial e afirmam que um prolongado período de apreciação cambial pode prejudicar o saldo comercial e a participação da manufatura no valor adicionado, afetando negativamente as inversões na atividade produtiva e a rentabilidade das exportaçôes e vendas domésticas.

Em contraponto, outros autores não acreditam na existência de um processo de desindustrialização na economia brasileira, sob o argumento de que o país passa por uma reestruturação produtiva ou pelo realinhamento da indústria aos padrões da economia global. Nessa direção, Nakahodo e Jank (2006) e Nassif (2008) ressaltam que o aumento das exportaçóes de commodities nos anos 2000 não foi suficiente para caracterizar uma perda de dinamismo dos setores de maior teor tecnológico, nem um processo generalizado de realocação dos recursos produtivos dos setores com tecnologias intensivas em escala, diferenciada e science-based para as indústrias baseadas em recursos naturais e em trabalho.

Adicionalmente, Barros e Pereira (2008) e Jank et al. (2008) apontam que a abertura comercial promoveu a terceirização de atividades não essenciais, transferindo parte do valor da produção e do emprego para o setor de serviços, sem que houvesse perda de produção industrial, sendo que a apreciação cambial promoveu a queda dos preços de máquinas e equipamentos importados, permitindo a modernização da indústria.

Bonelli e Pessôa (2010) destacam que a perda relativa de participação da indústria de transformação no PIB foi maior quando avaliada a preços correntes do que a preços constantes e esteve atrelada a momentos de recessão e/ou crise externa, 
contudo, os dados de produtividade e investimento fixo não sinalizam desindustrialização. Os autores advertem que a perda de participação brasileira na produção manufatureira mundial ocorreu porque o país tinha uma indústria muito maior do que o nível permitido pelo grau de desenvolvimento econômico nos anos 1970, o que a fez passar por uma correção do excesso de peso no contexto internacional.

Torres e Silva (2012) argumentam que certos indicadores utilizados pela literatura para avaliar as alterações do padrão industrial podem gerar conclusões equivocadas a respeito das mudanças na estrutura produtiva nacional. A participação da indústria no PIB sofre oscilações em função de alterações metodológicas nas séries de dados e mudanças organizacionais ocorridas na indústria. E a razão VTI/VBPI (Valor da Transformação Industrial/Valor Bruto da Produção Industrial) pode ser afetada pela apreciação cambial que estimula as importaçōes de insumos, elevando o VTI e sinalizando maior adensamento da cadeia produtiva, ao passo que teria ocorrido o contrário.

No âmbito subnacional, a discussão sobre os efeitos e a dinâmica do processo de desindustrialização ainda é pouco explorada. No contexto regional, Veríssimo e Silva (2013) apontam que a participação de produtos básicos nas exportações de todas as regiōes brasileiras elevou-se ao longo da década de 2000, sendo que, para as Regiōes Norte, Nordeste e Sudeste, foi possível notar uma contribuição da taxa de câmbio real apreciada e dos altos preços das commodities para a alavancagem das exportações de produtos básicos.

Cruz e Santos (2011) constatam um processo de reestruturação do setor produtivo baseado na desconcentração industrial dos tradicionais polos manufatureiros de São Paulo e Rio de Janeiro, com crescimento do número de microrregiōes industriais, principalmente no Centro-Oeste e Sul (Paraná e Santa Catarina). A região que mais perdeu neste processo, o Sudeste, tendeu a se especializar em indústrias de maior teor tecnológico, com ganhos de emprego nestes segmentos, aparentemente mais afetados por economias de aglomeração do que por incentivos fiscais.

Libânio (2008) destaca que a emergência da China no comércio internacional beneficiou os exportadores brasileiros nas vendas de produtos básicos. Já os exportadores de manufaturas mais elaboradas foram prejudicados, o que demonstra certa complementariedade da pauta exportadora de alguns estados em relação à demanda chinesa. Sobre Minas Gerais, o autor aponta que, como o estado é fortemente ligado à exportação mineral e agrícola, o comércio com a China no curto prazo se mostra benéfico ao crescimento econômico estadual, porém, no longo prazo, esta relação pode intensificar o caráter primário-exportador da economia mineira. 
Arriel e Castro (2010) assinalam que, no período 1996-2007, a participação da indústria de Goiás no PIB estadual apresentou forte crescimento por meio das políticas de fomento à atividade produtiva via incentivos fiscais. $\mathrm{O}$ perfil produtivo de Goiás sofreu notáveis transformações, destacando o surgimento da cadeia farmo-química e o ganho de peso da indústria metal-mecânica, apesar da ainda dominância de setores ligados aos diferenciais locais, como a agroindústria e a indústria extrativa mineral.

Já Rosendo e Brito (2011) e Sobral (2013) afirmam que o estado do Rio de Janeiro sofre uma histórica tendência de declínio da indústria, sendo que a forte expansão do valor de transformação industrial fluminense, no período pós-2000, não alterou este quadro, podendo significar um aprofundamento das cadeias industriais em setores ligados a recursos naturais, uma vez que a indústria extrativa mineral, petróleo e gás exerce grande influência na economia estadual.

Teixeira e Rodolfo (2012) observam que as políticas de fomento à indústria adotadas pelos governos federal e estadual não foram suficientes para conter a redução relativa da indústria em Santa Catarina. Em linha, Cavalieri et al. (2013) argumentam que as políticas econômicas pouco atrativas ao investimento produtivo resultaram em perda de importância relativa da indústria catarinense, com diminuição da produção e do emprego industrial na economia estadual. Todavia, Cario et al. (2013) descartam a possibilidade de desindustrialização absoluta no estado, dado que o emprego formal no setor industrial e o valor bruto da produção industrial catarinense cresceram expressivamente desde 1998.

No caso do Paraná, Scatolin et al. (2007) e Wasques (2012) alegam que não existe desindustrialização, pois, embora declinante no tempo, a participação do valor adicionado industrial no PIB paranaense manteve-se superior à média nacional desde 2001, sendo tal resultado derivado das políticas econômicas de abertura comercial, da elevada taxa de juros e do câmbio apreciado. Contudo, os autores destacam que o estado foi relativamente menos afetado por estes eventos quando comparado a outras Unidades da Federação, porque houve elevação da participação de exportações de alta e média-alta tecnologia no período 1996-2010.

Tendo em vista os argumentos alçados pela literatura, observa-se que a discussão sobre desindustrialização não é consensual. Os autores que concordam com a existência desse processo na economia nacional defendem, principalmente, que as políticas macroeconômicas adotadas a partir de 1990, como câmbio apreciado, elevadas taxas de juros e abertura comercial, prejudicaram o desempenho da indústria de transformação em relação ao comportamento dos setores mais intensivos 
em recursos naturais (processo denominado "desindustrialização relativa"). Outros trabalhos refutam a existência do problema, aderindo ao argumento de que tal contexto promoveu uma reestruturação da cadeia produtiva ou realinhamento desta aos padrōes globais.

A literatura sobre desindustrialização nos estados sugere que, desde a década de 1990, a matriz industrial subnacional passa por transformações. Os estados do Sudeste, em especial São Paulo e Rio de Janeiro, cuja industrialização se deu antes dos demais estados e de maneira mais concentrada e aprofundada, tiveram redução da participação da indústria no produto estadual e do número de empregados nessa atividade. De outro lado, regiôes originalmente alijadas do processo de industrialização, como Centro-Oeste, Nordeste e porçôes do Sul, ganharam participação da indústria no produto total, em função de vários fatores que buscaram desconcentrar a atividade industrial dos grandes centros do país, como políticas públicas de desenvolvimento e instrumentos fiscais (guerra fiscal). Todavia, para além daquelas razões, uma parte dessa transformação pode ser apontada como fruto de uma dinâmica mais ampla que resulta em especialização da indústria em setores ligados às vantagens comparativas (intensivas em recursos naturais) nas diversas regiôes do país.

\section{Perfil industrial de Minas Gerais}

A indústria em Minas Gerais respondeu por cerca de 10\% da atividade industrial nacional em 2012 (FJP, 2014), estando fundamentada em atividades de baixa densidade tecnológica (extrativa, baixa e média-baixa tecnologia), com pouca expressividade da indústria de alto conteúdo tecnológico. A mineração de ferro equivaleu a cerca de $65 \%$ da produção nacional, sendo que o grande aumento da demanda mundial, especialmente chinesa, pela commodity incentivou grandes investimentos das mineradoras, contribuindo para a expansão da indústria extrativa no VTI estadual. As exportações do estado são realizadas por grandes empresas (especialmente mineradoras) e mais da metade delas, em 2014, constituiu-se de minério de ferro (40\%) e café (14\%) (BRASIL, 2015). Assim, percebe-se que a conformação da matriz industrial mineira é relevante para a composição exportadora do Brasil, já que muitos dos principais produtos exportados pelo país possuem forte ligação com as atividades produtivas do estado, como a extração de minério de ferro, a atividade siderúrgica, a cafeicultura e a fabricação de veículos.

A análise do PIB de Minas Gerais segundo setores da atividade econômica (Tabela 1) revela que a participação do valor adicionado (VA) da indústria foi 
relativamente estável no período 2000-2012, em torno de 31,3\%. Em 2000, cerca de $32 \%$ do produto mineiro originou-se da atividade industrial, diminuindo para 29,4\% em 2012. Entretanto, a composição interna do VA industrial sofreu alteração: o peso relativo da atividade extrativa foi ampliado (de 3,4\% para 6\%) em detrimento das atividades de transformação (queda de $18 \%$ para $13,6 \%$ ), embora o ganho mais significativo de participação da indústria extrativa no PIB mineiro tenha ocorrido no pós-crise internacional (2010-2012).

TABELA 1

Composição do PIB, por setor de atividade econômica

Estado de Minas Gerais - 2000-2012

\begin{tabular}{|c|c|c|c|c|c|c|c|c|c|c|c|}
\hline \multirow{3}{*}{ Ano } & \multirow{2}{*}{\multicolumn{2}{|c|}{ Agropecuária }} & \multicolumn{6}{|c|}{ Indústria } & \multirow{2}{*}{\multicolumn{2}{|c|}{ Serviços }} & \multirow{3}{*}{$\begin{array}{c}\text { PIB (2) } \\
\text { Em R\$ } \\
\text { bilhóes } \\
\text { (3) }\end{array}$} \\
\hline & & & \multicolumn{2}{|c|}{ Extrativa } & \multicolumn{2}{|c|}{$\begin{array}{c}\text { Transfor- } \\
\text { maçáo }\end{array}$} & \multicolumn{2}{|c|}{ Total (1) } & & & \\
\hline & $\begin{array}{c}\text { Em R\$ } \\
\text { bilhóes } \\
\text { (3) }\end{array}$ & $\%$ & $\begin{array}{c}\text { Em R\$ } \\
\text { bilhóes } \\
\text { (3) }\end{array}$ & $\%$ & $\begin{array}{c}\text { Em R\$ } \\
\text { bilhōes } \\
\text { (3) }\end{array}$ & $\%$ & $\begin{array}{c}\text { Em R\$ } \\
\text { bilhóes } \\
\text { (3) }\end{array}$ & $\%$ & $\begin{array}{c}\text { Em R\$ } \\
\text { bilhóes } \\
\text { (3) }\end{array}$ & $\%$ & \\
\hline 2000 & 9,3 & 10,5 & 3,0 & 3,4 & 15,9 & 18,0 & 27,8 & 31,5 & 51,1 & 57,9 & 88,2 \\
\hline 2001 & 8,4 & 9,4 & 2,4 & 2,7 & 15,7 & 17,6 & 25,7 & 28,8 & 55,1 & 61,7 & 89,3 \\
\hline 2002 & 9,3 & 10,1 & 2,6 & 2,8 & 15,8 & 17,2 & 26,2 & 28,6 & 56,3 & 61,4 & 91,7 \\
\hline 2003 & 10,2 & 10,4 & 3,1 & 3,2 & 17,8 & 18,1 & 29,7 & 30,3 & 58,3 & 59,4 & 98,1 \\
\hline 2004 & 10,8 & 9,9 & 3,9 & 3,6 & 22,1 & 20,1 & 36,9 & 33,7 & 61,9 & 56,4 & 109,6 \\
\hline 2005 & 10,4 & 9,3 & 4,1 & 3,7 & 21,0 & 18,9 & 36,1 & 32,5 & 64,8 & 58,2 & 111,3 \\
\hline 2006 & 10,1 & 8,4 & 3,8 & 3,1 & 22,4 & 18,5 & 38,5 & 31,8 & 72,4 & 59,8 & 121,0 \\
\hline 2007 & 10,4 & 8,0 & 3,5 & 2,7 & 24,1 & 18,6 & 40,9 & 31,5 & 78,4 & 60,4 & 129,8 \\
\hline 2008 & 13,5 & 9,5 & 5,9 & 4,1 & 26,8 & 18,8 & 46,0 & 32,2 & 83,5 & 58,4 & 143,0 \\
\hline 2009 & 12,7 & 9,0 & 4,0 & 2,9 & 25,0 & 17,8 & 42,4 & 30,0 & 86,0 & 61,0 & 141,1 \\
\hline 2010 & 13,8 & 8,5 & 11,2 & 6,9 & 28,7 & 17,6 & 54,6 & 33,6 & 94,2 & 57,9 & 162,5 \\
\hline 2011 & 15,4 & 9,2 & 13,5 & 8,0 & 25,7 & 15,3 & 55,2 & 32,8 & 97,6 & 58,0 & 168,2 \\
\hline 2012 & 14,1 & 8,6 & 9,9 & 6,0 & 22,4 & 13,6 & 48,4 & 29,4 & 102,2 & 62,0 & 164,8 \\
\hline
\end{tabular}

Fonte: Fundação João Pinheiro - FJP; Instituto Brasileiro de Geografia e Estatística - IBGE. Elaboração dos autores. (1) A indústria total envolve os setores extrativo, de transformação, construção civil e energia e saneamento.

(2) Valor adicionado, desconsiderando impostos.

(3) Em reais de 2000.

Os dados mostram que todos os setores da atividade econômica em Minas Gerais tiveram ganhos reais de valores, elevando o PIB real do estado entre 2000 e 
2012. Esse resultado reflete o efeito quantum, como se pode ver pela Tabela 2, que retrata as taxas reais de crescimento da produção extrativa, de transformação e do PIB de Minas Gerais e do Brasil.

TABELA 2

Taxas reais de crescimento da indústria extrativa, de transformação e do PIB Estado de Minas Gerais e Brasil - 2003-2012

\begin{tabular}{c|c|c|c|c|c|c}
\hline \multirow{2}{*}{ Anos } & \multicolumn{3}{|c|}{ Minas Gerais } & \multicolumn{3}{c}{ Brasil } \\
\cline { 2 - 7 } & $\begin{array}{c}\text { Extrativa } \\
(\mathbf{1})\end{array}$ & $\begin{array}{c}\text { Transformação } \\
(\mathbf{1})\end{array}$ & PIB & $\begin{array}{c}\text { Extrativa } \\
(\mathbf{1})\end{array}$ & $\begin{array}{c}\text { Transformação } \\
(\mathbf{1})\end{array}$ & PIB \\
\hline 2003 & 9,4 & 0,5 & 1,39 & 4,9 & 0,1 & 1,22 \\
2004 & 11,7 & 4,9 & 5,87 & 3,8 & 7,9 & 5,66 \\
2005 & 13,1 & 4,5 & 3,96 & 10,9 & 3,1 & 3,15 \\
2006 & 8,8 & 4,3 & 3,89 & 7,4 & 2,4 & 4,00 \\
2007 & 12,4 & 7,9 & 5,61 & 5,9 & 6,0 & 6,01 \\
2008 & $-0,4$ & 1,8 & 5,18 & 3,8 & 3,0 & 5,02 \\
2009 & $-25,1$ & $-10,1$ & $-3,97$ & $-8,9$ & $-7,0$ & $-0,23$ \\
2010 & 31,9 & 11,3 & 8,92 & 13,5 & 10,0 & 7,57 \\
2011 & 1,5 & $-0,3$ & n.d. & 2,2 & 0,3 & 3,92 \\
2012 & $-0,3$ & 1,7 & n.d. & $-0,5$ & $-2,4$ & 1,76 \\
\hline
\end{tabular}

Fonte: Fundação João Pinheiro - FJP; Instituto Brasileiro de Geografia e Estatística - IBGE. Elaboração dos autores. (1) Proxy dada pela variação da produção física industrial, disponível a partir de 2003.

A produção física da indústria extrativa cresceu, em média, mais do que a indústria de transformação em Minas Gerais (6,3\% contra 2,6\%) e no Brasil (4,3\% contra 2,3\%), entre 2003 e 2012, e as indústrias de transformação mineira e nacional tiveram desempenhos parecidos. O PIB real mineiro também acompanhou a trajetória de crescimento do PIB real brasileiro, sendo que a crise internacional afetou drasticamente o desempenho do estado e da nação em 2009, com queda ligeiramente mais acentuada para Minas Gerais, em conjunto com a retração física das atividades extrativas e de transformação para as duas unidades de análise.

A Tabela 3 sistematiza alguns dos indicadores usualmente tratados na literatura para refletir alterações no padrão da atividade industrial, cuja análise pode sinalizar alguma evidência preliminar de perda de relevância da indústria na geração de produto e emprego para Minas Gerais, sendo eles: VTI, pessoal ocupado, produtividade e a razão VTI/VBPI, conforme o grau de intensidade tecnológica das atividades. 


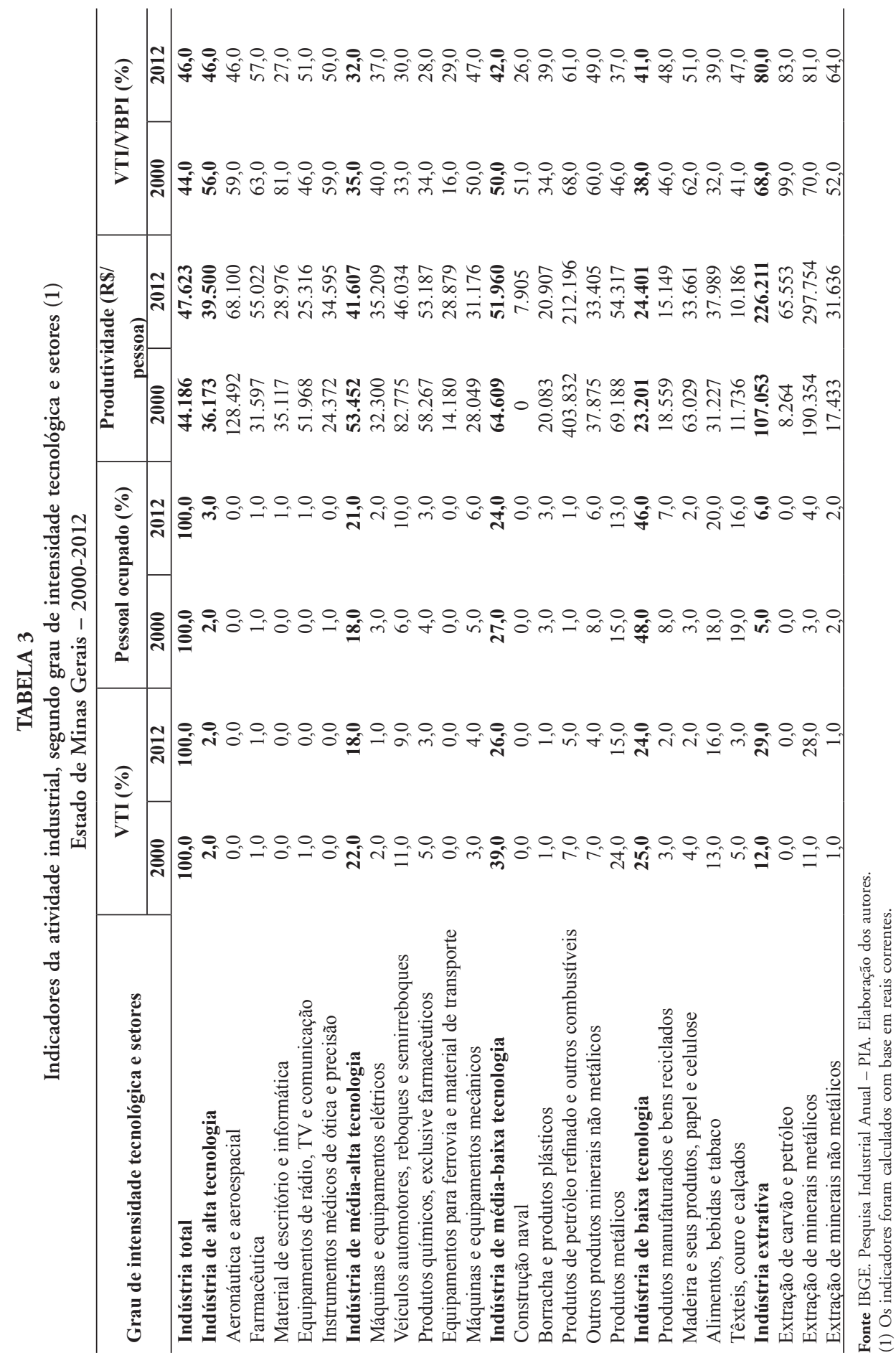


A análise da composição do VTI de Minas Gerais de acordo com a intensidade tecnológica evidencia que, em termos relativos, houve expressivo ganho de participação das atividades extrativas, entre 2000 e 2012, em relação aos demais setores industriais, em especial quando comparadas aos segmentos de média-alta e média-baixa tecnologia. Inclusive, ressalta-se a perda de participação no VTI de setores tradicionais da indústria de transformação mineira, como produtos metálicos (-9 p.p.) e outros produtos minerais não metálicos (-3 p.p.), que fazem parte da indústria de conteúdo tecnológico médio-baixo, além de veículos automotores (-2 p.p.) no segmento de conteúdo tecnológico médio-alto. Embora, em termos absolutos, os setores da indústria mineira tenham lidado com aumentos dos valores de VTI no período (ver Tabela 1 do Anexo), tais evidências sugerem uma mudança na composição da intensidade tecnológica em prol dos setores industriais mais intensivos em recursos naturais, com perda de relevância dos setores de menor conteúdo tecnológico, na direção do conceito de desindustrialização relativa. ${ }^{1}$

Assim, os dados mostram que, em 2000, a contribuição dos setores de baixa, média-baixa e média-alta tecnologia para o VTI estadual foi de, respectivamente, $25 \%, 39 \%$ e $22 \%$, enquanto as atividades ligadas à exploração de recursos naturais contribuíram com $12 \%$ do total. Pouco mais de uma década depois, a indústria extrativista passou a compor $29 \%$ do VTI, ao passo que os três grupos industriais citados reduziram suas parcelas para 24\%,26\% e 18\%, nesta ordem. A indústria de alta tecnologia, cuja contribuição relativa já era baixa, manteve sua participação em torno de $2 \%$.

Em relação ao emprego na indústria mineira, cabe destacar que houve um aumento expressivo do número total de pessoas ocupadas (62\%) entre 2000 e 2012 (ver Tabela 1 do Anexo). Este movimento ascendente ocorreu em todos os setores industriais, independentemente da categoria tecnológica. Em termos relativos, as categorias industriais também mantiveram aproximadamente as mesmas participaçôes no emprego industrial, com pequenos ganhos para a indústria extrativa e de alta tecnologia (1 p.p. para ambas) e para o grupo de média-alta tecnologia (3 p.p.). As atividades de baixa tecnologia tiveram seu peso reduzido em 2 p.p. e as de média-baixa tecnologia reduziram-se em 3 p.p. Desse modo, pela análise da participação relativa do emprego industrial, as evidências são pouco robustas para caracterizar desindustrialização relativa em Minas Gerais.

1 Este trabalho utiliza o conceito de desindustrialização "relativa", conforme exposto em Oreiro e Feijó (2010), segundo o qual os setores da atividade industrial dotados de maior conteúdo tecnológico perdem participação relativa aos setores de menor valor agregado ou baseados em recursos naturais. Nesse sentido, mesmo que não haja decréscimo nos indicadores das atividades industriais (o que configuraria a chamada desindustrialização "absoluta"), haveria desindustrialização em função da menor relevância dos setores de maior intensidade tecnológica para os resultados estaduais. 
Tendo em vista que tanto o número absoluto de empregos quanto o valor adicionado na atividade industrial aumentaram no período, é preciso avaliar a evolução da produtividade dos trabalhadores na indústria mineira, pois a hipótese de desindustrialização fica prejudicada se atrelada a uma redução da participação do emprego industrial que é acompanhada de ganhos de produtividade. Assim, verifica-se que o total da indústria em Minas Gerais obteve ganhos de produtividade do trabalho entre 2000 e 2012. Este resultado foi acompanhado pela indústria de alta tecnologia (especialmente farmacêutica e instrumentos médicos de ótica e precisão), que lida com mão de obra mais especializada, mas também pelos setores de baixa tecnologia (alimentos, bebidas e tabaco) e pela indústria extrativa (com destaque para a extração de minerais metálicos). Contudo, as indústrias de média-alta (veículos automotores e produtos químicos) e média-baixa tecnologias (petróleo refinado, produtos metálicos e outros produtos minerais não metálicos) perderam produtividade. Nestes casos, os empregos gerados não resultaram em aumento equivalente do valor transformado industrial, comprometendo a contribuição dessas atividades para o desempenho da indústria mineira.

Os dados da razão VTI/VBPI, que é normalmente tratada na literatura como uma medida da capacidade das atividades industriais de agregar valor na produção, apontam pequena elevação desta relação para a indústria total (2 p.p.) no período. $\mathrm{O}$ aumento mais significativo do indicador foi verificado para a indústria extrativa (12 p.p.), enquanto os setores de alta, média-alta e média-baixa tecnologia, possuidores de maiores capacidades de transbordamento, foram aqueles em que o índice mais se reduziu. O grupo de veículos automotores (média-alta) teve redução de 3 p.p. no indicador e o grupo de produtos metálicos (média-baixa) diminuiu 9 p.p.

A leitura tradicional da queda da razão VTI/VBPI nas atividades de maior intensidade tecnológica sugere que tais setores podem estar importando maior quantidade de insumos e transferindo parte da agregação de valor para o exterior, ao passo que os segmentos menos relevantes do ponto de vista de conteúdo tecnológico passam a agregar mais valor nacionalmente, como é o caso da indústria extrativa, cuja cadeia de produção é relativamente mais curta, com pouca importação. Contudo, a análise deste indicador como medida de adensamento da cadeia produtiva deve ser feita com cautela, visto que as variaçóes cambiais podem afetar os custos operacionais dos insumos importados, influenciando no VTI, sem que isso tenha se traduzido de fato em desmonte de cadeias produtivas provocado por um processo de aumento de importações. 
Os dados da pauta comercial de Minas Gerais (Tabela 4) evidenciam que apenas a indústria extrativa ampliou a participação nas exportações estaduais, passando de 29\% em 2000 para 54\% em 2013. A indústria de alta tecnologia manteve sua posição de pouca significância nas vendas externas do estado, enquanto os setores de média-alta, média-baixa e baixa tecnologia reduziram sua participação, respectivamente, de $18 \%$, $26 \%$ e $27 \%$ para $10 \%$, $13 \%$ e $23 \%$, no mesmo período.

TABELA 4

Exportações e importaçôes, segundo grau de intensidade tecnológica

Estado de Minas Gerais - 2000-2013

\begin{tabular}{|c|c|c|c|c|c|c|c|c|}
\hline \multirow{3}{*}{$\begin{array}{c}\text { Grau de } \\
\text { intensidade } \\
\text { tecnológica }\end{array}$} & \multicolumn{4}{|c|}{ Exportaçōes } & \multicolumn{4}{|c|}{ Importaçôes } \\
\hline & \multicolumn{2}{|c|}{2000} & \multicolumn{2}{|c|}{2013} & \multicolumn{2}{|c|}{2000} & \multicolumn{2}{|c|}{2013} \\
\hline & $\begin{array}{c}\text { Em US\$ } \\
\text { milhoes } \\
(1)\end{array}$ & $\%$ & $\begin{array}{c}\text { Em US\$ } \\
\text { milhóes } \\
(1)\end{array}$ & $\%$ & $\begin{array}{c}\text { Em US\$ } \\
\text { milhóes } \\
(1)\end{array}$ & $\%$ & $\begin{array}{c}\text { Em US\$ } \\
\text { milhóes } \\
(1)\end{array}$ & $\%$ \\
\hline Total & 6.712 & 100,0 & 33.437 & 100,0 & 2.779 & 100,0 & 12.648 & 100,0 \\
\hline Alta tecnologia & 33 & 0,0 & 82 & 0,0 & 73 & 3,0 & 397 & 3,0 \\
\hline $\begin{array}{l}\text { Média-alta } \\
\text { tecnologia }\end{array}$ & 1.220 & 18,0 & 3.184 & 10,0 & 1.792 & 64,0 & 8.530 & 67,0 \\
\hline $\begin{array}{l}\text { Média-baixa } \\
\text { tecnologia }\end{array}$ & 1.720 & 26,0 & 4.346 & 13,0 & 285 & 10,0 & 1.240 & 10,0 \\
\hline Baixa tecnologia & 1.810 & 27,0 & 7.644 & 23,0 & 287 & 10,0 & 1.197 & 9,0 \\
\hline Extrativa & 1.923 & 29,0 & 18.181 & 54,0 & 342 & 12,0 & 1.284 & 10,0 \\
\hline
\end{tabular}

Fonte: Ministério do Desenvolvimento, Indústria e Comércio Exterior. Secretaria de Comércio Exterior - Secex. Elaboração dos autores.

(1) Em dólares correntes.

De outro lado, as indústrias extrativa e de baixa tecnologia tiveram pequenas quedas de participação nas importações, passando de $12 \%$ e $10 \%$ em 2000 para $10 \%$ e $9 \%$ em 2013, respectivamente. A atividade de alta tecnologia, que também é pouco expressiva quanto às importações, manteve participação estável (3\%), o mesmo acontecendo com a indústria de média-baixa intensidade tecnológica (10\%). O setor com mais peso nas importaçōes mineiras é o de média-alta tecnologia, cuja participação passou de $64 \%$ para $67 \%$ no período. Assim, apenas para este último, é possível inferir algum processo de substituição de produção interna por importações.

O expressivo aumento de preço dos produtos minerais a partir de 2009 pode ter contribuído para estimular a concentração da pauta exportadora mineira em torno da atividade extrativa. Coligado à elevação dos preços das commodities, o histórico cambial também serve de argumento para a literatura defensora de que 
taxas de câmbio apreciadas tendem a assegurar o ganho de participação relativa de setores dotados de vantagens comparativas estáticas diante dos setores mais dinâmicos e intensivos tecnologicamente, para os quais a manutenção de uma taxa de câmbio em patamar mais depreciado é condição importante para sua inserção no mercado externo.

Em suma, os indicadores da atividade industrial em Minas Gerais sugerem uma alteração na configuração tecnológica da indústria mineira, no sentido de que segmentos de média-alta e média-baixa tecnologia perderam relevância nos resultados industriais (exceto no indicador de emprego), ao passo que as atividades mais ligadas à exploração de recursos naturais tiveram um ganho de peso expressivo, compensando a perda dos setores mais tradicionais. Com isso, quando se visualizam os dados para a indústria mineira na sua totalidade, as evidências de desindustrialização são pouco robustas, uma vez que a perda do valor adicionado da indústria geral no PIB do estado é pouco significativa. Todavia, deve-se atentar para o fato de o estado estar lidando com um avanço significativo da sua indústria extrativa na geração de produto e em todos os indicadores abordados, enquanto a indústria de transformação perde contribuição no PIB, VTI, produtividade e exportações, especialmente naqueles segmentos que concentram maior peso na estrutura produtiva do estado, ou seja, os de média-alta e média-baixa intensidade tecnológica.

\section{Análise econométrica}

Tendo em vista a deterioração dos indicadores de desempenho da indústria de transformação de Minas Gerais analisados na seção anterior, torna-se relevante averiguar, ainda que em termos preliminares, alguns dos determinantes econômicos que justificam aqueles resultados. Desse modo, na sequência, este trabalho investiga os efeitos da taxa de câmbio real, preços das commodities, taxa de juros e abertura comercial sobre a produção industrial (extrativa e de transformação) mineira. $\mathrm{O}$ intuito é avaliar se algumas variáveis listadas pela literatura como determinantes da perda de relevância da atividade industrial na economia são significantes para a análise do caso de Minas Gerais.

A especificação dos modelos foi feita com base em trabalhos sobre desindustrialização nacional, em que autores como Bresser-Pereira e Marconi (2008) e Oreiro e Feijó (2010) apontam a relevância da taxa de câmbio real e dos preços internacionais das commodities para sinalizar um processo de desindustrialização relativa por doença holandesa. Ademais, as variáveis grau de abertura comercial e taxa de juros foram 
incorporadas nas estimações para avaliar um possível processo de desindustrialização decorrente das políticas econômicas (abertura financeira e comercial) implementadas no país, que podem ter incentivado um padrão de especialização ricardiano, conforme argumentam Palma (2005) e Cano (2012).

Nesta direção, a análise é pautada pela estimação de dois modelos:

Modelo I: INDTRANSF $=\mathrm{f}($ TCREF, IPCOM, ABERT, SELIC $)$

Modelo II: INDEXTRAT $=\mathrm{f}($ TCREF, IPCOM, ABERT, SELIC $)$

Sendo:

- INDTRANSF: produção física da indústria de transformação de Minas Gerais, para captar o desempenho real desta indústria no estado.

- INDEXTRAT: produção física da indústria extrativa de Minas Gerais, para captar o desempenho real da indústria extrativa.

- TCREF: taxa de câmbio real efetiva - produtos manufaturados, que assinala o efeito do contexto cambial sobre os resultados da indústria mineira.

- IPCOM: preços das commodities não energéticas (excluem preços de petróleo e derivados, dado a pouca relevância do produto na matriz industrial mineira), para avaliar o efeito dos preços dos produtos primários em uma possível especialização regressiva em commodities.

- ABERT: grau de abertura comercial - soma das exportações e importações em relação ao PIB de Minas Gerais - proxy para avaliar se a abertura comercial favoreceu a substituição de produção industrial interna por importações.

- SELIC: taxa de juros Over-Selic trimestral anualizada, proxy para o estímulo ao investimento na atividade industrial.

Todas as variáveis são trabalhadas em logaritmo natural do número índice das séries (média $2005=100$ ). Os dados utilizados são trimestrais para o período 2002-T1 a 2013-T4, e foram obtidos a partir do Instituto Brasileiro de Geografia e Estatística (IBGE), Banco Central do Brasil (BCB), Fundo Monetário Internacional (IMF), Ministério do Desenvolvimento, Indústria e Comércio Exterior (MDIC) e Fundação João Pinheiro (FJP).

Havendo evidências de desindustrialização, os choques da taxa de câmbio real devem afetar positivamente a produção industrial mineira, sendo que se espera 
o efeito contrário para os choques dos preços das commodities. Assim, conforme Bresser-Pereira e Marconi (2008), a depreciação cambial e preços menores para as commodities devem estimular a atividade industrial, melhorando sua competitividade, ao passo que o câmbio apreciado e preços favoráveis aos produtos primários seriam propícios à especialização em bens intensivos em recursos naturais. Adicionalmente, taxas de juros elevadas e maior abertura comercial devem desestimular a indústria mineira, como sugerem Palma (2005) e Cano (2012), pois tal contexto pode limitar os investimentos produtivos e promover substituição da produção interna por importações, especialmente de bens manufaturados, cuja produção interna é menos eficiente do que a internacional.

A investigação utiliza análise de cointegração e estimação de Vetores de Correção de Erros (VEC). Duas variáveis são cointegradas se for observada entre elas uma relação de longo prazo ou de equilíbrio. Formalmente, diz-se que existe um equilíbrio de longo prazo quando $X_{t}^{\prime} \beta=0$, isto é, o vetor $\beta$, chamado vetor de cointegração, define uma combinação linear entre os elementos de $\mathrm{X}_{\mathrm{t}}$ perfeita no sentido de seguir uma tendência em comum, sem desvio.

$\mathrm{O}$ teste de Johansen, utilizado para detectar a existência de cointegração entre as séries, define o posto da matriz $\theta$ e estima os vetores de cointegração contidos na matriz $\beta$ a partir de uma normalização destes vetores, o que permite identificar as matrizes $\alpha$ (ajustamento de curto prazo) e $\beta$ (cointegração de longo prazo).

As informações do teste de Johansen são empregadas para especificar o modelo VEC, o qual consiste em um modelo de vetores autorregressivos (VAR) convencional, que utiliza o resíduo das séries cointegradas para melhor ajustar o sistema estimado. O VAR com variáveis diferenciadas omite informações relevantes na medida em que os resíduos da cointegração não são incluídos no modelo. O VEC corrige este problema ao incorporar os resíduos das séries cointegradas nas estimações para ligar o comportamento das variáveis no curto prazo com o seu valor no longo prazo.

Dado que a análise de cointegração requer a utilização de séries integradas em primeira ordem, a estacionariedade das séries foi testada, e as variáveis se mostraram estacionárias em primeira diferença. Além disso, foram estimados os modelos VAR, sendo que, com base no critério de Schwarz, o modelo II (indústria extrativa) apresentou melhor ajuste com uma defasagem, enquanto para o modelo I (indústria de transformação) foram necessárias duas defasagens. Em seguida, o teste de Johansen foi aplicado para verificar a existência de cointegração entre as séries e obter o número de vetores cointegrantes. As estatísticas do traço e do máximo autovalor 
indicaram a existência de pelo menos um vetor de cointegração para o modelo II e pelo menos dois vetores para o modelo I. ${ }^{2}$

Com base nestes diagnósticos preliminares, os modelos VEC foram estimados para captar a relação de longo prazo entre as variáveis (Tabela 5).

TABELA 5

Estimativas do modelo de vetores de correção de erros (VEC)

\begin{tabular}{lcc|c|c}
\hline Modelos & TCREF & IPCOM & ABERT & SELIC \\
\hline \multirow{2}{*}{ Modelo I: INDTRANSF } & $0.811277^{*}$ & 0.247146 & $-0.581716^{*}$ & $-1.224971^{*}$ \\
& $(0.24880)$ & $(0.18908)$ & $(0.19415)$ & $(0.13524)$ \\
\multirow{2}{*}{ Modelo II: INDEXTRAT } & $-1.636990^{*}$ & $0.746433^{* *}$ & 0.038516 & $2.045711^{*}$ \\
& $(0.43232)$ & $(0.40279)$ & $(0.55309)$ & $(0.31477)$ \\
\hline
\end{tabular}

Fonte: Elaboração dos autores a partir dos resultados do Eviews 7.

${ }^{*} \mathrm{e}^{* *}$ coeficientes estatisticamente significantes ao nível de $1 \%$ e $5 \%$, respectivamente.

Nota: Desvio-padrão entre parêntesis.

As evidências sinalizam efeitos positivos (esperados) da taxa de câmbio real sobre a indústria de transformação de Minas Gerais (uma depreciação cambial de $1 \%$ estimula a produção industrial de transformação em $0,81 \%)$. Este resultado sugere a importância de um câmbio mais competitivo para o desempenho favorável da atividade de transformação no estado. Tal evidência está alinhada aos argumentos de Bresser-Pereira e Marconi (2008), que apontam um efeito prejudicial da apreciação cambial a longo prazo sobre a competitividade da indústria de transformação, ensejando uma possível perda relativa de participação da atividade industrial de conteúdo tecnológico mais elaborado na geração de produto e emprego.

Para a indústria extrativa, o efeito da taxa de câmbio real se mostrou negativo (uma apreciação cambial em $1 \%$ estimula a produção da indústria extrativa mineira em 1,64\%), ou seja, uma taxa de câmbio competitiva não parece importante para o desempenho desta indústria. Tal fato pode ser explicado pela natureza do setor, que é atrelada à exploração de recursos naturais, em que as vantagens de custo relativas e o contexto de demanda externa favorável podem ser mais relevantes do que a condição cambial para inseri-lo no mercado internacional.

Os efeitos dos preços das commodities foram positivos (contrário ao esperado), embora apenas para a atividade extrativa tal resultado tenha sido estatisticamente significante, indicando que um aumento de $1 \%$ nos preços das commodities estimula a produção daquela indústria em $0,75 \%$. Novamente, justifica-se que, sendo

2 Os resultados dos testes econométricos se encontram no Anexo deste trabalho. 
a indústria extrativa baseada, sobremaneira, em recursos naturais e trabalho, o contexto de elevados preços externos das commodities tende a beneficiar o desempenho industrial do estado neste caso.

A abertura comercial apresenta efeito negativo sobre a atividade de transformação mineira, sinalizando que um aumento de $1 \%$ no grau de abertura comercial do estado implica queda de $0,58 \%$ da produção da indústria de transformação. Este resultado é condizente com os pressupostos de Palma (2005) e Cano (2012). Desse modo, o contexto de maior abertura comercial não se mostra favorável ao desempenho deste tipo de indústria, sinalizando a substituição de produção interna por importações, sobretudo, de bens de maior valor agregado. Para a indústria extrativa, a influência do grau de abertura comercial se mostra positiva, mas tal resultado não obteve significância estatística.

A taxa de juros exerce uma influência negativa sobre a produção da indústria de transformação (o aumento da taxa de juros básica da economia em 1\% desestimula a produção da indústria de transformação mineira em 1,22\%). Esta evidência se alinha aos resultados apontados na literatura, segundo os quais as políticas macroeconômicas desde meados da década de 1990 contribuíram para prejudicar as condições de investimento e consumo da indústria de transformação, especialmente, de conteúdo tecnológico mais elaborado. Para a indústria extrativa, o sinal da taxa de juros foi positivo (contrário ao esperado). Aparentemente, o contexto macroeconômico interno foi menos relevante para a produção extrativa mineira, que se mostra mais dependente de variáveis relacionadas ao contexto externo de preço e de demanda favoráveis.

Ressalta-se que as evidências empíricas obtidas se alinham aos resultados observados pela análise dos indicadores do perfil industrial de Minas Gerais na seção 3 deste trabalho, os quais já haviam sinalizado avanço da atividade extrativa no estado e perda de relevância dos segmentos da indústria de transformação, em especial dos setores de média-baixa e média-alta tecnologia. Desse modo, a hipótese de desindustrialização em Minas Gerais fica restrita à indústria de transformação, que se mostrou influenciada pelas condiçóes cambiais adversas, pela abertura comercial e pela taxa de juros. Os resultados para a indústria extrativa não sinalizam prejuízo daquelas variáveis para tal atividade, pois esta vem se desenvolvendo e obtendo melhores resultados em Minas Gerais independentemente das condições internas da economia no período mais recente. 


\section{Considerações finais}

Este artigo analisou o perfil industrial de Minas Gerais, tendo como linha norteadora a discussão a respeito de desindustrialização. Partiu-se da hipótese de que o contexto de apreciação cambial, altos preços internacionais das commodities, taxas de juros elevadas e abertura comercial, vivenciado em boa parte dos anos 2000, pode reforçar a especialização da estrutura produtiva e exportadora do estado em produtos intensivos em recursos naturais, implicando desempenho menos favorável da indústria de transformação, em especial quando comparado ao desempenho da indústria extrativa.

Inicialmente, a estrutura industrial de Minas Gerais foi caracterizada conforme alguns indicadores usualmente tratados pela literatura para se avaliar a desindustrialização. Nesse sentido, a perda de participação da indústria de transformação no PIB de Minas Gerais, juntamente com o aumento da participação relativa do VTI, da razão VTI/VPBI e das exportações na indústria extrativa vis-à-vis a menor participação dessas variáveis em segmentos tradicionais da indústria de transformação mineira (média-alta e média-baixa tecnologia), sugere um processo de especialização produtiva nos setores intensivos em recursos naturais, beneficiado pela alta no preço das commodities desde 2003 e pela demanda externa favorável, especialmente chinesa. Todavia, os dados de emprego e de produtividade do trabalho não permitem chegar à mesma conclusão, visto que houve aumento do número de empregos em muitos dos setores industriais, acompanhado de ganhos de produtividade.

Em seguida, para justificar a perda de desempenho da indústria de transformação mineira, conforme os indicadores industriais demonstraram, relativamente aos melhores resultados obtidos pela atividade extrativa, o trabalho analisou os efeitos do câmbio, preços das commodities, abertura comercial e juros sobre a produção da indústria de transformação e extrativa de Minas Gerais.

As evidências assinalam impacto favorável de uma taxa de câmbio real competitiva (depreciada) para a indústria de transformação, sugerindo que, num quadro de apreciação cambial, o estado pode enfrentar um movimento de desindustrialização de longo prazo. Além disso, as políticas de elevadas taxas de juros e abertura comercial foram negativas sobre a atividade de transformação.

Já o contexto de preços elevados das commodities aparentemente mostrou-se benéfico à atividade extrativa, que é intensiva em recursos naturais, aumentando seu peso na composição industrial mineira, sendo que as demais variáveis analisadas 
não afetaram negativamente o desempenho desta atividade. Assim, a hipótese de desindustrialização nesta indústria não pode ser corroborada.

Em linhas gerais, a indústria mineira apresentou tendência de maior participação de produtos primários (indústria extrativa) na estrutura produtiva e exportadora ao longo dos anos 2000, com deterioração da condição tecnológica da indústria de transformação, o que pode apresentar menores condições dinamizadoras desta última sobre a economia estadual e nacional. Portanto, de forma crítica, o modelo empírico sugere que, em Minas Gerais, é relevante decompor a análise da atividade industrial nos dois segmentos que a representam, pois as evidências de desindustrialização são restritas à indústria de transformação. Em trabalhos futuros, caberia a estimação do modelo considerando a produção industrial mineira por grau de intensidade tecnológica, a fim de verificar se e quais setores podem ter sido adversamente afetados pelas variáveis econômicas relacionadas.

\section{Referências bibliográficas}

ARRIEL, M. F.; CASTRO, S. D. O perfil produtivo da indústria goiana. Conjuntura Econômica Goiana. Boletim trimestral, n. 15. Goiânia: Secretaria do Planejamento e Desenvolvimento do Estado de Goiás, 2010.

BARROS, O.; PEREIRA, R. R. Desmistificando a tese da desindustrialização: reestruturação da indústria brasileira em uma época de transformaçōes globais. In: BARROS, O.; GIAMBIAGI, F. (Orgs.). Brasil globalizado: o Brasil em um mundo surpreendente. Rio de Janeiro: Elsevier, 2008. p. 299-330.

BONELLI, R.; PESSÔA, S. A. Desindustrialização no Brasil: um resumo da evidência. Fundação Getúlio Vargas. Instituto Brasileiro de Economia, março 2010 (Texto para discussão, n. 7).

BRASIL. Ministério do Desenvolvimento, Indústria e Comércio Exterior. Estatísticas do Comércio Exterior. 2015. Disponível em: <http:/www.mdic.gov.br//sitio/interna/interna. php?area=5\&menu=1076>. Acesso em: 20 jun. 2015.

BRESSER-PEREIRA, L. C.; MARCONI, N. Existe doença holandesa no Brasil? In: FÓRUM DE ECONOMIA, 4. Anais... São Paulo: Fundação Getúlio Vargas, 2008.

CANO, W. A desindustrialização no Brasil. Economia e Sociedade, Campinas, v. 21, número especial, p. 831-851, 2012.

CARIO, S. A. F.; NICOLAU, J. A.; SEABRA, F.; BITTENCOURT, P. Processo de desindustrialização em Santa Catarina. Florianópolis: Federação das Indústrias do Estado de Santa 
Catarina (Fiesc), Núcleo de Economia Industrial e da Tecnologia - Universidade Federal de Santa Catarina (UFSC), 2013.

CAVALIERI, H.; CARIO, S. A. F.; FERNANDES, R. L. Estrutura industrial brasileira e de Santa Catarina: alguns indícios de desindustrialização. Indic. Econ. FEE, Porto Alegre, v. 40, n. 3, p. 81-104, 2013.

CLARK, C. The conditions of economic progress. 3. ed. Londres: Macmillan, 1957.

CRUZ, B. O.; SANTOS, I. R. S. Dinâmica do emprego industrial no Brasil entre 1990 e 2009: uma visão regional da desindustrialização. Rio de Janeiro: Ipea, 2011 (Texto para discussão, n. 1673).

FJP - Fundação João Pinheiro. Produtos e serviços. Produto Interno Bruto de Minas Gerais. 2014. Disponível em: <http://www.fjp.mg.gov.br/index.php/produtos-e-servicos1/2745-produto-interno-bruto-de-minas-gerais-pib-2>. Acesso em: 23 set. 2014.

IBGE - Instituto Brasileiro de Geografia e Estatística. Pesquisa Industrial Anual - PIA. Disponível em: <http://www.sidra.ibge.gov.br/bda/acervo/acervo9.asp? $e=c \& p=P K \& z=t \& o=22>$. Acesso em: 23 set. 2014.

IMF - International Monetary Fund. Data and statistics. IMF primary commodity prices. March, 2014. Disponível em: <http://www.imf.org/external/np/res/commod/index.asp>. Acesso em: 23 set. 2014.

JANK, M. S.; NAKAHODO, S. N.; IGLESIAS, R.; MOREIRA, M. M. Exportações: existe uma "doença brasileira"? In: BARROS, O.; GIAMBIAGI, F. (Orgs.). Brasil globalizado: o Brasil em um mundo surpreendente. Rio de Janeiro: Elsevier, 2008. p. 331-352.

KALDOR, N. Causes of the slow rate of economic growth of the United Kingdom: an inaugural lecture. Cambridge: Cambridge University Press, 1966.

LIBÂNIO, G. O crescimento da China e seus impactos sobre a economia mineira. Revista Economia \& Tecnologia, Curitiba, v. 4, n. 2, p. 103-110, 2008.

MARCONI, N.; ROCHA, M. Taxa de câmbio, comércio exterior e desindustrialização precoce - o caso brasileiro. Economia e Sociedade, Campinas, v. 21, número especial, p. 853-888, 2012.

NAKAHODO, S. N.; JANK, M. S. A falácia da doença holandesa no Brasil. São Paulo: Institute for International Trade Negotiations, 2006 (Documento de pesquisa).

NASSIF, A. Há evidências de desindustrialização no Brasil? Revista de Economia Política, São Paulo, v. 28, n. 1, p. 72-96, 2008. 
OREIRO, J. L.; FEIJÓ, C. A. Desindustrialização: conceituação, causas, efeitos e o caso brasileiro. Revista de Economia Política, São Paulo, v. 30, n. 2, p. 219-232, abr./jun. 2010. PALMA, J. G. Quatro fontes de desindustrialização e um novo conceito de doença holandesa. São Paulo: Federação das Indústrias do Estado de São Paulo, 2005.

ROSENDO, R. C.; BRITTO, J. Evolução da densidade industrial do estado do Rio de Janeiro: análise comparativa com os estados de Sudeste brasileiro - 2000/2005. In: ENCONTRO NACIONAL DE ECONOMIA, 39. Anais... Foz do Iguaçu, 2011.

ROWTHORN, R.; RAMASWANY, R. Growth, trade and deindustrialization. International Monetary Fund, Research Department, 1999 (Working paper).

SCATOLIN, F. D.; DA CRUZ, M. J. V.; PORCILE, G.; NAKABASHI, L. Desindustrialização? Uma análise comparativa entre Brasil e Paraná. Indic. Econ. FEE, Porto Alegre, v. 35, n. 1, p. 105-120, 2007.

SOBRAL, B. L. B. A falácia da "inflexão econômica positiva”: algumas características da desindustrialização fluminense e do "vazio produtivo" em sua periferia metropolitana. Cadernos do Desenvolvimento Fluminense, Rio de Janeiro, n. 1, 2013.

TEIXEIRA, F. W.; RODOLFO, F. Trajetória recente do setor industrial catarinense: uma análise com base nos dados da produção física. Revista NECAT, Florianópolis, ano 1, n. 1, p. 22-30, 2012.

TORRES, R. L.; SILVA, H. C. Uma crítica aos indicadores usuais de desindustrialização no Brasil. In: ENCONTRO NACIONAL DE ECONOMIA, 40. Anais... Porto de Galinhas: Anpec, dezembro 2012.

TREGENNA, F. Characterizing deindustrialization: an analysis of changes in manufacturing employment and output internationally. Cambridge Journal of Economics, Cambridge, v. 33, n. 3, 2009.

VERÍSSIMO, M. P.; SILVA, C. G. Taxa de câmbio, preços de commodities e exportações de produtos básicos nas regiōes brasileiras. Rev. Econ. NE, Fortaleza, v. 44, n. 3, p. 777-794, jul./set. 2013.

WASQUES, R. N. O fenômeno da desindustrialização: uma análise do caso paranaense no período 1990-2010. Revista Economia \& Tecnologia, Curitiba, v. 8, n. 1, p. 67-76, 2012. 


\section{Anexo - Resultados Complementares}

\section{TABELA 1}

Valor do VTI e pessoal empregado na indústria, segundo grau de intensidade tecnológica e setores Estado de Minas Gerais - 2000-2012

\begin{tabular}{|c|c|c|c|c|}
\hline \multirow{2}{*}{ Grau de intensidade tecnológica e setores } & \multicolumn{2}{|c|}{$\begin{array}{l}\text { VTI (em R \$ milhôes } \\
\text { correntes) }\end{array}$} & \multicolumn{2}{|c|}{$\begin{array}{l}\text { Pessoal } \\
\text { ocupado }\end{array}$} \\
\hline & 2000 & 2012 & 2000 & 2012 \\
\hline Indústria total & 24.210 & 42.367 & 547.911 & 889.625 \\
\hline Indústria de alta tecnologia & 470 & 892 & 12.993 & 22.582 \\
\hline Aeronáutica e aeroespacial & 46 & 57 & 358 & 837 \\
\hline Farmacêutica & 168 & 435 & 5.317 & 7.906 \\
\hline Material de escritório e informática & 21 & 168 & 598 & 5.798 \\
\hline Equipamentos de rádio, TV e comunicação & 136 & 126 & 2.617 & 4.977 \\
\hline Instrumentos médicos de ótica e precisão & 100 & 106 & 4.103 & 3.064 \\
\hline Indústria de média-alta tecnologia & 5.291 & 7.828 & 98.986 & 188.142 \\
\hline Máquinas e equipamentos elétricos & 521 & 572 & 16.130 & 16.246 \\
\hline Veículos automotores, reboques e semirreboques & 2.707 & 4.023 & 32.703 & 87.392 \\
\hline Produtos químicos, exclusive farmacêuticos & 1.305 & 1.456 & 22.397 & 27.375 \\
\hline $\begin{array}{l}\text { Equipamentos para ferrovia e material de } \\
\text { transporte }\end{array}$ & 21 & 51 & 1.481 & 1.766 \\
\hline Máquinas e equipamentos mecânicos & 737 & 1.726 & 26.275 & 55.363 \\
\hline Indústria de média-baixa tecnologia & 9.389 & 11.208 & 145.321 & 215.703 \\
\hline Construção naval & 0 & 2 & 30 & 253 \\
\hline Borracha e produtos plásticos & 301 & 631 & 14.988 & 30.181 \\
\hline $\begin{array}{l}\text { Produtos de petróleo refinado e outros } \\
\text { combustíveis }\end{array}$ & 1.665 & 2.227 & 4.123 & 10.495 \\
\hline Outros produtos minerais não metálicos & 1.581 & 1.831 & 41.743 & 54.812 \\
\hline Produtos metálicos & 5.842 & 6.516 & 84.437 & 119.962 \\
\hline Indústria de baixa tecnologia & 6.072 & 9.956 & 261.709 & 408.015 \\
\hline Produtos manufaturados e bens reciclados & 795 & 941 & 42.836 & 62.117 \\
\hline Madeira e seus produtos, papel e celulose & 938 & 742 & 14.882 & 22.043 \\
\hline Alimentos, bebidas e tabaco & 3.116 & 6.798 & 99.784 & 178.948 \\
\hline Têxteis, couro e calçados & 1.223 & 1.476 & 104.207 & 144.907 \\
\hline Indústria extrativa & 2.987 & 12.483 & 27.902 & 55.183 \\
\hline Extração de carvão e petróleo & 1 & 51 & 121 & 778 \\
\hline Extração de minerais metálicos & 2.755 & 11.956 & 14.473 & 40.154 \\
\hline Extração de minerais não metálicos & 232 & 451 & 13.308 & 14.256 \\
\hline
\end{tabular}

Fonte: IBGE. Pesquisa Industrial Anual - PIA. Elaboração dos autores. 
TABELA 2

Testes de raiz unitária

\begin{tabular}{lcc|c}
\hline Série & t-ADF & t-PP & t-KPSS \\
\hline DINDTRANSF & $-12,22^{*}$ & $-8,88^{*}$ & 0,28 \\
DINDEXTRAT & $-8,56^{*}$ & $-10,69^{*}$ & $0,50^{* *}$ \\
DIPCOM & $-5,79^{*}$ & $-5,05^{*}$ & 0,25 \\
DTCREF & $-4,98^{*}$ & $-4,80^{*}$ & 0,26 \\
DABERT & $-5,09^{*}$ & $-11,17^{*}$ & 0,27 \\
DSELIC & $-5,40^{*}$ & $-2,81^{* * *}$ & 0,05 \\
\hline
\end{tabular}

Fonte: Elaboração dos autores a partir dos resultados do Eviews 7.

$\mathrm{D}$ indica a primeira diferença.

*, ** e *** indicam rejeição de $\mathrm{H} 0$ a $1 \%, 5 \%$ e $10 \%$ de significância, respectivamente.

Valores críticos do ADF e PP (H0: Raiz Unitária): $1 \%(-3,58), 5 \%(-2,93)$.

Valores críticos do KPSS (H0: Estacionariedade): $1 \%(0,74), 5 \%(0,46)$.

TABELA 3

Seleção do VAR

\begin{tabular}{c|c|c|c|c}
\hline Modelos & Defasagens & AIC & SC & HQ \\
\hline \multirow{3}{*}{ Modelo I } & 1 & -12.0843 & -10.8556 & -11.6312 \\
& 2 & -13.1095 & $-10.8568^{*}$ & -12.2788 \\
& 3 & $-13.5114^{*}$ & -10.2348 & $-12.3031^{*}$ \\
& 4 & -13.4576 & -9.1570 & -11.8717 \\
Modelo II & 1 & -10.6693 & $-9.4406^{*}$ & -10.2162 \\
& 2 & -11.3679 & -9.1152 & $-10.5372^{*}$ \\
& 3 & -11.6744 & -8.3977 & -10.4660 \\
\hline
\end{tabular}

Fonte: Elaboração dos autores a partir dos resultados do Eviews 7.

* indica defasagem selecionada pelo critério de informação.

AIC, SC, HQ: Critérios de informação de Akaike, Schwarz e Hannan-Quinn.

TABELA 4

Estatística do traço

\begin{tabular}{c|c|c|c|c}
\hline \multirow{2}{*}{ Modelos } & N. de vetores de & \multirow{2}{*}{ Traço } & \multicolumn{2}{|c}{ Valores críticos } \\
\cline { 4 - 5 } & cointegração & & $\mathbf{5 \%}$ & $\mathbf{1 \%}$ \\
\hline \multirow{3}{*}{ Modelo I } & Nenhum* $^{*}$ & 159.57 & 76.07 & 84.45 \\
& Ao menos 1* & 76.01 & 53.12 & 60.16 \\
& Ao menos 2** & 39.33 & 34.91 & 41.07 \\
& Ao menos 3 & 16.44 & 19.96 & 24.60 \\
& Nenhum $^{*}$ & 93.06 & 59.46 & 66.52 \\
& Ao menos 1** & 45.21 & 39.89 & 45.58 \\
& Ao menos 2 & 20.47 & 24.31 & 29.75 \\
& Ao menos 3 & 7.67 & 12.53 & 16.31 \\
\hline
\end{tabular}

Fonte: Elaboração dos autores a partir dos resultados do Eviews 7.

* e ** rejeição da hipótese nula, respectivamente, ao nível de $1 \%$ e $5 \%$ de significância estatística. 
TABELA 5

Estatística do máximo autovalor

\begin{tabular}{|c|c|c|c|c|}
\hline \multirow{2}{*}{ Modelos } & \multirow{2}{*}{$\begin{array}{c}\text { N. de vetores } \\
\text { de cointegraçáo }\end{array}$} & \multirow{2}{*}{$\begin{array}{l}\text { Máximo } \\
\text { autovalor }\end{array}$} & \multicolumn{2}{|c|}{ Valores críticos } \\
\hline & & & $5 \%$ & $1 \%$ \\
\hline \multirow{4}{*}{ Modelo I } & Nenhum* & 83.56 & 34.40 & 39.79 \\
\hline & Ao menos $1^{*}$ & 36.68 & 28.14 & 33.24 \\
\hline & Ao menos $2^{* *}$ & 22.89 & 22.00 & 26.81 \\
\hline & Ao menos 3 & 13.27 & 15.67 & 20.20 \\
\hline \multirow{4}{*}{ Modelo II } & Nenhum* & 47.84 & 30.04 & 35.17 \\
\hline & Ao menos $1^{* *}$ & 24.74 & 23.80 & 28.82 \\
\hline & Ao menos 2 & 12.79 & 17.89 & 22.99 \\
\hline & Ao menos 3 & 7.53 & 11.44 & 15.69 \\
\hline
\end{tabular}

Fonte: Elaboração dos autores a partir dos resultados do Eviews 7.

* e ** rejeição da hipótese nula, respectivamente, ao nível de 1\% e 5\% de significância estatística. 